\title{
FIXAÇÃO DE TARIFAS - DNAEE - COMPETÊNCIA
}

\section{PARECER}

\section{I}

A consulta tem como objeto a definição da competência do DNAEE em matéria tarifária, após o advento da Lei $\mathrm{n}^{\circ} 774$, de 18 do mesmo mês e ano. São formulados os seguintes quesitos:

316 
$1^{\circ}$ - Pode o DNAEE indeferir a fixação de tarifas e recusar-se a homologá-las?

$2^{\circ}$ - Sob que motivos?

$3^{\circ}$ - Deve a recusa ser justificada?

$4^{\circ}$ - Pode o DNAEE exigir a inserção de cláusula nos contratos de suprimento que subordinem o regime de tarifas a novas regras administrativas (Portarias, Resoluções etc.) que vieram a ser editadas?

Especificamente indaga-se sobre os limites da competência do DNAEE e a função que a de esta reservada, em face da nova legislação.

A resposta à consulta impõe a qualificação prévia de princípios e critérios que condicionam a economia das concessões de energia elétrica.

\section{II}

O equilíbrio financeiro nas concessões de serviço público.

A regra do equilíbrio econômico-financeiro do contrato administrativo transcede à sua definição no direito positivo e se tornou um princípio geral de direito que visa a manter a proporcionalidade entre as obrigações das partes, tal como expressa ou implícita no acordo de vontade.

A estabilidade financeira nos contratos administrativos e investimentos estrangeiros buscou apoio, durante o Segundo Reinado (notadamente a partir de 1870), nas cláusulas de garantia de juros e nas cláusulas-ouro ou de câmbio ao par (ver, a respeito, nosso estudo sobre "Correção monetária no direito administrativo" in Revista de Direito Administrativo, vol. 97, p. 10-12 e in Perspectivas del derecho público en la segund mitad del siglo XX, Madrid, 1969, tomo IV, p. 855 e ss).

Foi, contudo, a frequêencia de instabilidade na ordem econômica, tornando excessivamente onerosas as obrigações contratuais, que fomentou a crescente tendência de revisāo dos contratos diante de intolerável agravamento da álea ordinária prevista pelas partes.

Em face da realidade econômica subjacente, ao princípio da imutabilidade formal das convenções foi progressivamente se substituindo a garantia do reequilibrio intrínseco entre as suas obrigações. $O$ fato econômico passa a moldar a aplicação da lei (ex facto oritur jus).

O início da construção jurisprudencial e doutrinária encontrou raízes na ressurreição de antigo brocado do direito romano.

Atribui-se aos post glosadores, com origem presumível em texto do Digesto (XII-4-8) e no Direito canônico a revivescência da cláusula rebus sic stantibus segundo a qual, nos contratos a termo ou de execução sucessiva, pressumia-se implícita a permanência do estado de fato contemporâneo ao contrato ( $C o n$ tractus qui habent tractum sucessivum el dependentian de futuro rebus sic stantibus intelliguntur - entendem-se como se as coisas assim permanecessem).

Florescente no direito medieval, a cláusula desaparece com o predomínio do individualismo jurídico e o sentido absoluto da autonomia de vontade.

A crise financeira no início do século atual fez ressurgir, porém, no direito administrativo francês, a presença da cláusula, como fundamento da revisão de prestações vincendas.

A regra do equilíbrio financeiro do contrato administrativo consolidou-se a partir do famoso, arresto do Conselho de Estado no caso da Compagnie Générale Française des Tramways (21 de março de 1910) no sentido de que sempre que se agravassem os encargos do outro contratante por ato unilateral da Administração caiba a esta indenizar a álea extraordinária acrescida ao contrato (ver Haurlou, La jurisprudenci administrative de 1892 a 1929, tomo III, p. 470 e ss.)

Esta formulação da necessária equivalência entre as obrigações, fundada no princípio da equidade, veio a ser traduzir ao princípio da chamada equação financeira do contrato administrativo, objeto de especial definição de Pequignot (Théorie générale du contrat administratif, 1945, p. 448 e segs.).

A correlação básica entre as obrigaçōes bilateralmente constituídas deve ser restaurada quando uma delas se diferencia em detrimento da estabilidade do contrato, impondo-se a correspondente revisão da obrigação da parte responsável pela violação. 
Pequignot define, com nitidez, a fórmula da equação financeira do contrato administrativo:

"L'équilibre du contrat de droit prive est statiqui et du typ $a=b$. Si l'une des parties a un contrat de droit privé mécoinnait ses obligations, elle comment un faute, le système contractual est irrémediablement rompu. L'équilibre du contrat administraif est dynamique et du typ $a / b=a^{\prime} / b^{\prime}$. Sil l'Administration substitue une obligation à l'obligation originaire, la remuneration de son concontractant qui étaif b à l'origine deviendra b' et le système contractuel, ainsi réquilibré sera mante nu" (Juris classeur administratif, 1953, fascículo $511, \mathrm{n}^{\circ} 237$ ).

A continuada perturbação da ordem financeira deu continuidade a tendência revisionista dos contratos, inclusive nas relações privadas, mediante a crescente adoção de critérios de reajustes de preços contratuais, a princípios pela acolhida da teoria da imprevisão e pelo nascimento de cláusulas preventivas da ruptura do equilibrio entre as obrigações. Nesse sentido prosperam aí cláusulas móveis na composição dos preços contratuais e, em seguida, se generalizou a aceitação da regra da correção monetária do valor das obrigações de pagar, sempre em coerência com o princípio capacital da justa correspondência entre as obrigações, ou, para usar a expressão de Leon Blum "L'equivalence honnête" entre as obrigações das partes que é "La base, le fondement même de l'accord, du consentiment" (parecer no citado caso da Compagnie Générale Française des Tranways, de 21.3.1910 - texto completo In Revue de Droit Public et de la Science Politique, $\mathrm{n}^{\circ} 27$, p. 270 e ss).

Em tese de concurso a cátedra de Direito Administrativo (1960) - incorporada ao nosso livro "Direito Administrativo" — edição Saraiva - 1975 - demonstramos os fundamentos, no direito comparado e no direito brasileiro, da garantia da justa remunerado do concessionário de serviço público, que se elevou ao plano constitucional (art. $167, n^{\circ}$ II da Constituição de 1967/69) e, na Carta atual, é requisito implícito da política tarifária, como meio hábil para assegurar a prestação do ser- viço adequado (Constituição de 1988, art. 175, parágrafo único, $\mathrm{n}^{\circ} \mathrm{III}$ e IV).

Em acórdão, com abundante lastro doutrinário, que reconheceu a uma empresa de transporte aéreo o direito à indenização pela quebra de equilíbrio econômico-financeiro do contrato destaca o ilustre Relator que a Constituição em vigor consubstância o princípio do equilíbrio econômico-financeiro do contrato de concessão, visto que "o art. 175 da Constituição deve compreendido na visão do preceito geral inscrito no art. 37, XXI do mesmo Estatuto Fundamental" (Revista de Direito Administrativo - vol. 187, p. 295/303, acórdam do Tribunal Regional Federal da $1^{\text {a }}$ Região).

III

\section{$O$ critério anterior de fixação de tarifas}

O Código de Águas (Decreto $\mathrm{n}^{\circ} 24.643$, de 10 de julho de 1914) estipulou o princípio de revisão trienal de tarifas flexíveis, destinadas a garantir a estabilidade financeira das empresas concessionárias e a prestado de serviços adequado (art. 163 e 178).

A fixação de tarifas, calculadas sob a forma de serviço pelo custo, foi atribuída ao Serviço de Águas, órgão do Departamento Nacional de Produção Mineral (art. 178), sucedido pela Divisão de Águas (D.I. n 3.763, de 25 de outubro de 1941).

O tombamento das propriedades vinculadas aos serviço, cujo valor serve de base ao cálculo da remuneração do investimento, foi regulado no D.I. $\mathrm{n}^{\circ} 3.128$, de 10 de março de 1941.

As alterações legais subsequientes foram consolidadas mediante a regulamentação geral dos serviços de energia elétrica, aprovada peto Decreto $n^{\circ} 41.019$, de 26 de fevereiro de 1957, que definiu a competência da Divisão de Águas para fiscalização técnica e econômico-financeira das empresas concessionárias (art. 12 e 13).

Como expressão dessa competência, conferiu-se à Divisão de Águas, órgão de fiscalização do serviço, o poder de fixado das tarifas com a tríplice finalidade de regular o regimento do serviço pelo custo, garantir a remunera- 
ção do investimento e vedar discriminações entre os consumidores (arts. 164 e 165).

Confirmou-se o princípio da revisão trienal das tarifas (art. 172) e o reajuste intermediário, a título precário, na ocorrência de variações nos elementos de cálculo do custo do serviço (art. 176).

O Decreto $n^{\circ} 62.724$, de 17 de maio de 1968 , inovou as normas de tarifado, estabelecendo critério de classificação dos consumidores, reafirmando a competência da fiscalização para regular o processo de cálculo das tarifas (art. 26), que é disciplinado na Portaria $n^{\circ} 96$, de 7 de junho de 1968, com a atribuição confirmada do Departamento Nacional de Águas e Energia para a estipulação dos preços a serem aplicados pelos concessionários aos fornecimentos de energia.

A fiscalização dos serviços de energia, na qual se insere a competência de fixação de tarifas, continuou afeta ao DNAEE na sucessão de modalidades de estrutura da administração direta da União, passando do Ministério da Agricultura para o Ministério de Minas e Energia, criado com a Lei $n^{\circ} 3.782$, de 22 de julho de 1960 , integrando-se, a seguir, no $\mathrm{Mi}$ nistério da Infra-Estrutura para retornar ao Ministério das Minas e Energia que se restaurou com a Lei ${ }^{\circ} 8.422$, de 13 de maio de 1992 (que convalidou a Medida Provisória $n^{\circ} 302$, de 10 de abril de 1992).

O Decreto $n^{\circ} 507$, de 23 de abril de 1992, editado com apoio na citada Medida Provisória $n^{\circ} 302$, prevê a competência do Departamento Nacional de Águas e Energia Elétrica para a definição dos níveis e as estruturas das tarifas de energia elétrica (art. II, $n^{\circ} \mathrm{VI}$ ). E a norma se repete na Portaria Ministerial $n^{\circ} 65$, de 11 de fevereiro de 1993, art. 18, item VI).

A par da legislação geral sobre correção monetária, o sistema tarifário de energia elétrica pautou-se por dois princípios fundamentais. A Lei $\mathrm{n}^{\circ} 5655$, de 20 de maio de 1971 'com alterações dos D.I. $n^{\circ} 1506$, de 23-12-76 e 1.849 , de 15.01 .81 ) instituiu o sistema de remunerado garantida de $10 \%$ a $12 \%$ sobre o investimento reconhecido e a progressiva equilização tarifária em todo o território nacional deveria ser implantada, como prescrevia o art. $4^{\circ}$ do D.I. $n^{\circ} 1.383$. de 26 de dezembro de
1974. criando-se, para esse fim. Conta de Resultados a Compensar (CRC) e a Reserva Nacional de Compensação de Remuneração (Rencor),

Em toda essa evolução do regime econômico-financeiro dos serviços subsiste, inalterada, a competência do Poder Concedente para determinar os preços de fornecimento de energia, a serem obedecidos pelos concessionários.

O direito subjetivo das empresas concessionárias à cobertura dos custos operacionais e à justa remuneração do capital aplicado no serviço transita pela legislação ordinária e, como assinalado, abrange o plano constitucional.

A fixação de tarifa é atribuição reservada ao Poder Concedente, por intermédio do órgão de fiscalização, a saber, o Departamento Nacional de Águas e Energia Elétrica (DNAEG).

Ainda que, em termos formais, as empresas concessionárias limitem a garantia de uma remuneração mínima de seus sentimentos, a política administrativa de contenção de custos de há muito provocava uma insuficiência de recursos e a acumulação de créditos na Conta de Resultados a Compensar, de difícil realização.

A continuidade dos déficits remuneração passaram a afetar a qualidade do serviço e a retardar a expansão de novos investimentos na medida do crescimento da demanda.

O reconhecimento desta crise operacional levou à recente reforma das bases financeiras do serviço de energia.

\section{IV \\ O novo regime tarifário}

A Lei $n^{\circ} 8.631$, de 4 de março de 1993 adotou novo regime tarifário nos serviços de energia elétrica, regulamentado pelo Decreto $n^{\circ} 774$, de 18 de março de 1993.

A iniciativa na fixação das tarifas, antes afeto ao órğo de fiscalização, passa à alçada do concessionário que deve calcular os níveis dos preços de fornecimento aos consumidores finais, ou os de suprimento às demais empresas, submetendo a proposta de novos valores homologado do poder concedente (arts. $17 \mathrm{e}$ 
$2^{\circ}$ da Lei $8.631 / 93$ e art. $1^{\circ}$ do Decreto $n^{\circ}$ 774/93.

A proposta deve atender à cobertura do custo do serviço, de modo a garantir a prestação de serviço adequado $\left(\$ 2^{\circ}\right.$ dos arts. $1^{\circ}$ e $2^{\circ}$ da Lei $n^{\circ} 8631$ e art. $2^{\circ}$ do Decreto $n^{\circ} 774$ ).

A proposta assim formulada será examinada pelo órgão competente (no caso, o Departamento Nacional de Águas e Energia Elétrica) que deverá se manifestar no prazo de quinze dias, homologando os níveis propostos, ou impugnando-os, expressa e motivadamente (arts. $1^{\circ}$ e $2^{\circ}$ da Lei $n^{\circ} 8.631$ e do Decreto $n^{\circ}$ 774).

A ausência de manifestação no prazo especificado equivale do concessionário. $O$ silêncio da Administração tem, em suma, efeito positivo, valendo como aprovação $\left(\$ 1^{\circ}\right.$ dos arts. $1^{\circ}$ e $2^{\circ}$ da Lei $n^{\circ} 8.631$ e $\$ 3^{\circ}$ do art. $2^{\circ}$ do Decreto $n^{\circ} 774$ ).

Transforma-se, por sua forma, a relação de competência na determinação dos preços de serviço.

Não apenas a fixação dos níveis iniciais de tarifas para à iniciativa do concessionário.

Igualmente incumbe, ao concessionário a iniciativa de reajuste periódico dos valores, destinado a recompor o poder aquisitivo das tarifas, mediante a utilização de fórmula parmétrica (art. $4^{\circ}$ da Lei $n^{\circ} 8.631$ ), cujos componentes estão previstos no ato regulamentar (art. $4^{\circ},\left(\S 1^{\circ}\right.$ e $2^{\circ}$ do Decreto $\left.n^{\circ} 774\right)$.

A proposta inicial do concessionário de logo deverá, indicar parâmetros que serão adotados nos reajustes subsequientes. $E$ a seu critério, poderá, ainda, o concessionário estabelecer programa gradual de recuperado dos níveis adequados das tarifas $\left(\S 2^{\circ}\right.$ e $4^{\circ}$ do art. $2^{\circ}$ do Decreto $n^{\circ} 774$ ).

O esquema inovador da fixação de tarifas, adotado na nova lei, atende ao princípio de transferir ao concessionário a responsabilidade de prover ao equilibrio financeiro da concessão, mediante a iniciativa do processo de fixação dos preços do serviço, cabendo ao órgão do poder concedente a atribuição do exame a posteriori, para verificação do justo valor da proposta.

O direito subjetivo do concessionário à tarifa inicial, como aos reajustes, de um lado, vin- cula-se à observância dos critérios básicos estipulados na lei e no regulamento, e, de outra parte, tem sua eficácia sujeita à condição suspensiva de homologação expressa, ou tácita. do poder concedente e - tratando-se de suprimento de energia - à celebração de contrato entre supridor e suprido como termo inicial de validade $\left(\S 2^{\circ}\right.$ do art. $3^{\circ}$ da Lei $\left.n^{\circ} 8.631\right)$.

A precedência atribuída, no novo modelo legal, ao ato de vontade do concessionário tem como finalidade dinamizar o processo de adequação tarifária, especialmente em face da supressão, na mesma lei, do regime de remuneração garantida e, por via de conseqüência, a extinção da Conta de Resultados a Compensar e da Reserva Nacional de Compensação de Remuneração (art. $3^{\circ}$ da Lei ${ }^{\circ} 8.681$ ).

Cessa para o concessionário, o crédito da diferença de insuficiência de remuneração do investimento, na previsão de que a peridicidade dos reajustes tarifários eliminará a defasagem na cobertura dos custos do serviço, nos quais se coloca a remuneração do investimento.

$\mathrm{Na}$ Exposição de Motivos $n^{\circ} 91$. de 23 de dezembro de 1992, pela qual os Ministros de Minas e Energia e da Fazenda e o Secretário do Planejamento submetem ao Presidente da República o projeto que se converteu na Lei $n^{\circ} 8.631$, então enumeradas as bases essenciais do modelo econômico-financeiro proposto:

a) a extinção da equalização tarifária e a transferência, aos concessionários, da responsabilidade das respostas tarifárias;

b) a supressão do regime de remuneração garantida e a consequiente extinção da CRC e da RENCOR;

c) a obrigatoriedade dos contratos de suprimento (item 16 de mencionada Exposição de Motivos).

A cessação do regime de remuneração garantida torna relevante a iniciativa do concessionário quanto à proposta inicial de novas tarifas atualizadas, bem como da periodicidade dos reajustes assecuratórios do equilíbrio econômico-financeiro na prestação de serviço adequado.

A ação revisora do órgão próprio do concedente deve manifestar-se, em prazo certo, tra- 
duzindo-se no ato homologatório, valendo o silêncio como manifestação de vontade.

Importa o novo regime legal em uma clara inversão de competências.

A liberdade tarifária é como regra, concedida ao concessionário, embora o seu exercício se vincule a parâmetros estabelecidos na lei e no respectivo regulamento.

A ação administrativa, atribuída ao DNAEE, configura-se como ato homologatório, ou seja, como procedimento posterior de controle de qualidade da proposta do concessionário não lhe cabendo substituí-la, ou predeterminar-lhe os respectivos valores.

Não mais incumbe ao concedente, como no regime anterior, a iniciativa de fixação de tarifas que a nova legislação outorga ao concessionário.

A competência do DNAEE deixa de ser primária, passando a sucessiva, na aferição da legalidade da proposta do concessionário.

\section{$\mathrm{V}$}

\section{Conceito e limites do poder normativo da} Administração

Como assinalado, o atual regime jurídico da concessão transfere ao concessionário a responsabilidade de iniciativa de tarifas na prestação do serviço que the é delegado, cabendo ao poder concedente a faculdade de fiscalizar a adequação da proposta, de forma a preservar o interesse público e a garantia de disponibilidade na fruição do serviço pelos usuários ou consumidores.

A lei complementada pelo regulamento, pré-determina as obrigações e direitos do concessionário e estabelece o procedimento de controle da eficiência e regularidade da prestação do, serviço, compreensiva da estipulação do preço a ela correspondente.

A fiscalização do serviço compreende tanto a avaliação do comportamento do concessionário como admite que as normas legais e regulamentares possam ser aditadas em instruções de serviço que qualifiquem a forma de prestação do serviço.

A competência do órgão físcalizador, a par da verificação dos atos do concessionário, al- cança também a faculdade de regular, em caráter de generalidade, o procedimento de observância, pelo concessionário, das regras legais, regulamentares e contratuais a serem atendidas.

Exerce, em suma, o órgão do concedente, em escala subordinada, poder normativo complementar à estrutura legal e regulamentar do serviço.

A Constituição atribui ao Presidente da República o poder regulamentar que tem por finalidade assegurar a fiel execução das leis (art. $84 n^{\circ}$ IV da Constituição de 1988 e equivalente norma em Constituições anteriores).

Não se esgota porém, na esfera presidencial o poder normativo do Executivo.

A formação do direito positivo, conforme a lição de KELSEN, opera em graus de sucessiva e decrescente hierarquia.

A concepção se inspira no desempenho dinâmico da função administrativa, em razão da continuidade e a flexibilidade que distingue, autorizando a complementado da lei emanada do Poder Legislativo. mediante atos administrativos de teor normativo.

Arrolando as fontes materiais de direito administrativo, tivemos oportunidade de recordar que o poder normativo do Estado:

"Se manifeste por meio de círculos concêntricos que vão, sucessivamente, da Constituição à lei material e formal, isto é, aquela elaborada pelos órgãos legislativos; desta aos regulamentos por meio dos quais o Presidente da República complementa e particulariza as leis; e, finalmente, aos atos administrativos gerais, originários das várias escalas de competência administrativa. São constantes as normas, de força obrigatória equivalente as leis e regulamentos, desde que a elas ajustadas, contidas em portarias, ordens de serviço, circulares; instruções, ou (como se casto atual) em meros despachos" (Revista de Direito Administrativo - vol. 46, p. 248).

Honrando-me com a citação dessa passa'gem, Helly Lopes Meirelles indicou, a seu turno, a graduado das normas administrativas em sua sucessiva hierarquia:

"É de elementar conhecimento que tanto no Direito Constitucional quanto no Direito Administrativo, as normas e os atos normativos 
obedecem a uma rígida hierarquia, insuscetível de inversão ou transposição pelo administrador ou pelo administrado. No nosso regime jurídico-constitucional as normas descem da Constituição da República, passando pelas leis ordinárias, decretos regulamentares, regimentos, resoluções e deliberações colegiadas. Daí para baixo os atos passam a outra categoria, sem normatividade e com menor abrangência, que é a dos atos ordinatórios. Mas, tanto naqueles, quantos nestes, os seus regramentos e o âmbito de incidência vão diminuindo do ápice da pirâmide das normas concebida por Kelsen - no qual se situa a Constituição, alta base, onde se encontrem os atos normativos inferiores sempre hierarquizados pelos superiores" (Estudos e Pareceres de Direito Público - vol. VII, p. 338).

No mesmo sentido, a lição de Gaston Jèze, mestre insígne francês, apontando a identidade ontológica entre as virias fontes formais de direito administrativo, independentemente da qualidade do autor do ato normativo:

- il n'y a pas de différence de nature juridique entre: $1^{\circ}$ - la loi proprement dite, c'. est-à-dire la règle de droit génerale et impersonnelle, formulée para les deux Chambres et promulguée para le Presidente de la Republique; $2^{\circ}$ - le décret-loi, c'est-à-dire la règle de droit générale impersonnelle, formulée, dans les périodes de dictadure par les indivi. dus que se sont proclamés dictateurs; $3^{\circ}-$ le décret-loi colonial, c'es-à-dire da règle de droit générale formulée par le Présidente de la Republique dans certaines colonies; $4^{\circ}$ le réglement d'administration publique, c'està-dire la règla de droit générale et impersonnelle formulée par le Présidente de la Répu. blique, aprés avis du Consell d'Etat, sur la invitation des Chambres; $5^{\circ}$ - le règlement simples, c'est-à-dire la règle de droit générale et impersonelte formulée par le President de la Republique ou par tout autre agent public investi du pouvoir reglementaire; $6^{\circ}-$ l'arrêt ministériel, l'instruction ministérelle, la circulaire ministérielle, en tant qu'il s'agit d'une règle de droit générale et impersonnelle formulée par un ministre dasn les cas où le ministre a le pouvoir règlementaire (Les principes generaux de Droit Administratif $-3^{2}$ edição $-1925-1^{\circ}$ volume - p. $28 /$ ss. grifos do original).

A substância de tais atos que materialmente fazem nascer uma norma jurídica secundária corresponde à noção daquilo que Duguit batizou com ato-regra:

Dès à présent, on voit apparâitre une première catégorie d'actes juridiques, ceux qui sont faits avec l'intention qu'il se produise une modification dans les règles de droit. $\mathrm{Ce}$ sont ces actes que nous appelons des actes-règles. Ils ont exlusivement le carctère objectif, puisi que à leur suite se produit uniquement une modification dans le domaine du droit objectif, sans qu'il soit touché en quoi que ce soit à la situation d'um ou de plusieurs individus déterminés.

Dans le droit public les règlements, les clauses règlementaires d'un act de concession, dans le droit privé les status d'une asso. ciation ou d'une société, les clauses d'une convention collective de travail sont des exemples très nets d'actes règles (Traité de Droit Constitutionel $-2^{a}$ edição - 1921 Tomo I - p. 221).

Não são apenas os atos legislativos do Congresso, ou os atos regulamentam do Presidente da República que se configuram como atos normativos, ou atos-regras. Também os atos administrativos que visam a criar aquela situação générale et impersonnelle, a que alude Jèze, são atos materialmente legislativos, compondo a base do ordenamento jurídicoadministrativo.

São os chamados atos administrativos gerais, que conforme a definição de Ranelletti, não se dirigem à regência de uma situação individual:

L'atto administrativo in senso formale può essere generale o speciale. É générale se la dichiarazione che costituisce l'atto amminis. trativo riguarda astrattamente una plurarità di persone o casi indeterminati e indeterminabili, cioè è générale e astratta. Tale, ad. es., un regolamento; tale una circolare con la


pendenti sulla interpretazione di una nuova legge, per assicurarne la unicitá dei criteri di applicazione (Oreste Ranelletti - Teoria de- 
gli atti amministrativi speciali $-7^{\mathrm{a}}$ edição 1945 - p. 2).

Os atol administrativos gerais, de conteúdo normativo, são atos-regra que, nos termos do conceito de Duez e Debeyre, exprimem" "une manifestation de volonté ayante pour objet la création", l'extinction ou la modification d'une situation juridique générale correspondendo ao degrau inferior da hierarquia em que os atos-regras se colocam (Paul Duez et Guy Debeyre - Traité de Droit Administratif - 1952 - p. $185 / 187$ - grifos do original).

À luz desses princípios, é lícito ao DNAEE emitir atos normativos que orientem à praticada competência agora atribuída aos concessionários para o impulso inicial do processo tarifário

O âmbito do poder normativo que, como acima esclarecido, é peculiar aos órgãos administrativos, está, contudo, subordinado ao conceito básico da hierarquia das fontes de direito.

Assim como o regulamento, como ato secundário, vincula-se à lei que visa a executar (secundum legem), o ato administrativo normativo tem como limite e parâmetro obrigatório as normas, princípios e critérios expressos ou implícitos constantes da lei e no regulamento, como ordenamentos superiores e imperativos.

Os princípios de reserva legal e de hierarquia de normas marcam a legalidade da ação normativa de autoridade administrativa competente ratione materiae.

$\mathrm{O}$ ato administrativo normativo tem como finalidade complementar e concretizar a norma legal ou regulamentar, que lhe serve de balizamento.

Não podem subverter-lhes o conteúdo ou o âmbito de incidência.

São atos subordinados que devem respeito à matriz superior, na graduação normativa e sucessiva de poder ordenatório.

\section{VI}

Após a promulgação da Lei n ${ }^{\circ} 8.631 / 93$, o DNAEE adquiriu, em matéria tarifária, uma posição distinta daquela que antes lhe indicava a legislação precedente.

A esta nova colocação ter-se-á de afeiçoar o eventual exercício do poder normativo que lhe incumbe na matéria.

Não the é dado emitir instruções ou regras que retirem ao concessionário a liberdade de iniciativa na proposta de níveis tarifários. A qualificação da latitude de competência do concessionário, como agente primário no procedimento tarifário, tem como esteio os ditames que a nova lei e seu regulamento preestabelecem.

O novo sistema retira ao DNAEE a competência primária de interferir no cálculo tarifário, reservando-a ao exame da proposta do concessionário, a fim de homologá-la ou repudiá-la, motivadamente, se ilegal.

A eventualidade de recursa ou não homologação de proposta tarifária ou de reajustes de tarifas, somente será cabivel quando estiverem eivadas de específico erro ou ilegalidade.

Não é lícito ao DNAEE pré-estabelecer forma ou critério de exercício da competência do concessionário, em acréscimo aos requisitos sociais.

Quer as propostas iniciais de novas tarifas, quer os futuros reajustes, atenderão ao procedimento expressamente adotado no novo regime, legal, respeitando-se a sucessão no tempo de iniciativa do concessionário e da homologação subsequiente pelo DNAEE.

Deste manifesto processo de competências sucessivas discrepa, a nosso ver, a recente Portaria $n^{\circ} 566$, de 3 de junho de 1993, segundo a qual o DNAEE adota, a título normativo limitações que não se coadunam com o modelo legal vidente.

Primeiramente, resolve o DNAEE

"não homologar os aumentos reais de tarifas nos contratos de suprimento assinados em cumprimento à Lei $n^{\circ} 8.681$, de 4 de março de 1993 e do Decreto $n^{\circ} 774$, de 18 março de 1993, em meses posteriores a outubro de 1993" (ar. $1^{\circ}$ ).

E, a seguir, avoca poder regulatório do processo tarifário, estipulando que

"os ajustes necessários para que as tarifas das empresas supridoras atinjam os respectivos níveis de custos serão objeto de portaria 
de revisão tarifária, cujos efeitos nas empresas supridas serão absorvidas através de fórmula paramétrica" (art. 20).

Em instruções dirigidas as concessionárias, - DNAEE avoca competência, que não se abriga no esquema da Lei $n^{\circ} 8.631 / 93$, no sentido de condicionar as propostas de novos níveis tarifários.

Assim, em ofício $n^{\circ} 165$, de 19 de abril de 1993, determina o teto que as tarifas de suprimento devem alcançar em seis meses e estabelece que essa forma de recuperado não poderá exceder a aumentos reais mensais de ordem de $8,77 \%$, sendo o primeiro aumento programado para 01.05.93. Ordena, ainda, que, atingido o nível estipulado, tarifa de suprimento manter-se-á estabilizada por prazo de seis meses, após o qual terão permitidos aumento de produtividade.

Norma equivalente foi estipulada para tarifas de fornecimento, com a fixação de aumentos reais de $6 \%$ a $8 \%$ e a regulação dos reajustes, atribuindo-se ao DNAEE e à Secretaria de Política Econômica do Ministério da Fazenda, o acompanhamento do processo de recomposição das tarifas de suprimento e de fornecimento de energia.

Em ofício-circular $n^{\circ} 273$, de 23 de abril de 1993, voltou o DNAEE a determinar, como condição para homologar tarifas de suprimento, "a adequação dos reajustes tarifários considerados nas propostas de recuperação gradual, aos indices máximos definidos por orientação superior, pelo período de 6 meses".

Em novo ofício-circular $n^{\circ} 340$, de 31 de maio de 1993, mais uma vez o DNAEE condiciona a iniciativa das concessionárias que, a par da norma regulamentar prevista no Decreto $\mathrm{n}^{\circ} 774 / 93$, também deverá estar "harmonizada com as diretrizes para a fase inicial do programa de recuperação tarifária".

Em Telex n 45, de 12 de maio de 1993, dirigido às concessionárias, o DNAEE renova a advertência de que não serão homologadas propostas tarifárias excedentes ao limite de $8,77 \%$ de aumento mensal no período de maio a outubro de 1993.

Agindo por essa forma o DNAEE retoma o comando do procedimento tarifário como se ainda subsistisse o regime anterior à Lei $n^{\circ}$ 8.631/93.

A inversão que é da essência do novo método de fixação tarifário, colocando em primeiro plano a proposta do concessionário, sujeita a homologação posterior, fica subvertida com a interferência administrativa prévia, estipulando limites à realidade tarifária que a lei de logo faculta implantar.

Atribuindo-se - e à Secretaria da Fazenda - uma espécie de teto para a recomposição tarifária, o DNAEE não apenas assume poder normativo que de lege não lhe foi conservado, como contraria o espírito do novo sistema em que a iniciativa do concessionário precede ao controle a posteriori da fiscalização do serviço.

Embora possivelmente inspirado no propósito de conter a cronologia de alta real dos preços de energia, objetivando uma política de contenção na economia, o ato normativo do DNAEE representa, no entanto, um excesso de poder não autorizado pela opção assumida pelo legislador quanto à nova sequiência do processo tarifário.

A liberdade que a lei nova concede ao concessionário para a retomada do equilibrio financeiro do serviço fica coartada pelo arbítrio de uma limitação máxima não estabelecida na lei e incompativel com suas diretrizes.

\section{VII}

Firmadas as premissas desenvolvidas nos tópicos precedentes, passamos a examinar aos quesitos propostos.

Tendo em vista a íntima conexão entre os quesitos $1^{\circ}, 2^{\circ}$ e $3^{\circ}$, oferecemos resposta conjunta.

$1^{\circ}$ - Pode o DNAEE indeferir a fixação de tarifas e recusar-se a homologá-las?

$2^{\circ}-$ Deve a recusa ser justificada?

Resposta - Tanto a fixação inicial de tarifas após a Lei $n^{\circ} 8.631 / 93$, como os reajustes, têm como ponto de partida a proposta formal do concessionário, submetida à homologação do órgão de físcalização do serviço, no caso, o DNAEE. 
No prazo de 15 dias, o concedente terá obrigatoriamente de se manifestar, importando o seu silêncio em homologação tácita:

A manifestação do DNAEE poderá traduzir-se em "expressa e formal inconformidade" (art. $2^{\circ}, \S 3^{\circ}$ do Decreto $n^{\circ} 774 / 93$ ), negando aprovação à proposta de concessionário (quer se trate de empresa distribuidora quer seja supridora) quando esta desatender aos princípios e critérios fixados na lei ou no regulamento.

Todavia, $o$ ato de recusa teria de ser motivado de forma clara e manifesta que possibilite a avaliação de sua pertinência.

A motivação obrigatória integra o ato e a realidade dos motivos invocados é requisito de legalidade, a ser aferido em grau de recurso hierárquico, pela via judicial.

Nulo que seja o ato de recusa se fundamentado em falso motivo, prevalece o princípio geral de eficácia da proposta do concessionário, de modo a garantir a continuidade do serviço e a preservação do princípio do equilíbrio financeiro, do contrato.

A declaração de nulidade tornará inexistente, pelo vício de legalidade, a manifestação negativa de vontade da Administração, fazendo operar a regra da homologação tácita da proposta.

$4^{\circ}$ - Pode o DNAEE exigir a inserção de cláusula nos contratos de suprimento que subordinem o regime de tarifas a novas regras administrativas (Portaria, Resoluções etc.) que vierem a ser editadas?

Resposta - Como assinalado, o poder normativo que permite ao DNAEE baixar instrução sobre o regime tarifário terá, necessaria- mente, de conformar-se aos ditames da lei e do regulamento.

Especialmente, impõe-se o respeito à nova sistemática que torna livre a proposta do concessionário dentro dos parâmetros e critérios legais e regulamentares.

$\mathrm{O}$ ato administrativo normativo é fonte de menor hierarquia que não pode se contrapor aos níveis superiores de formação do direito positivo, devendo a eles se submeter, seja em sua letra, seja em seu espírito.

A luz dessa regra elementar de hermenêutica, tivemos ensejo de analisar, em tópico precedente, a impropriedade de instruçōes e circulares do DNAEE, posteriores à vigência da Lei $n^{\circ} 8.631 / 93$, nas quais se pretende implantar limites percentuais à atualização das tarifas de suprimento e de fornecimento de energia elétrica, violando o novo esquema legal que tem como princípio e finalidade a aplicação de tarifas reais, com superação da defasagem acumulada nas tarifas do passado.

Será inócuo e ilícito pretender, mediante imposição de Cláusula Contratual ou por outra qualquer forma, impor restrição à iniciativa da proposta tarifária por parte do concessionário, que não estiver prevista na Lei ${ }^{\circ}$ 8.631/93, ou Decreto $n^{\circ} 774 / 93$, somente passíveis de alteração ou complementação por ato de igual hierarquia, respeitado ainda, quanto ao eventual exercício do poder regulamentar, a necessária subordinação ao ato legislativo superior.

É como nos parece, em face da consulta formulada.

Caio Tácito, professor emérito da Universidade do Estado do Rio de Janeiro. 